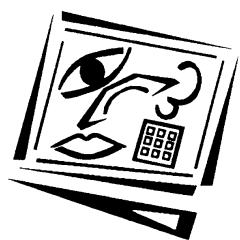

\title{
Students' self analysis of contributions to online asynchronous discussions
}

\author{
Elizabeth Murphy \\ Memorial University of Newfoundland \\ Jamie Loveless \\ Exploits Valley High (Maple Division), Grand Falls-Windsor, NL
}

\begin{abstract}
This paper presents an example of an approach that involves both the student and the instructor in the evaluation of an online discussion in a context of teaching and learning. According to this approach, the student conducts a self analysis of his or her contributions to the discussion, using criteria supplied in advance of the discussion. One student's four part self analysis of his contribution to an online discussion is presented to illustrate the approach. The self analysis focused on the number and length of postings, claims and grounds, and on knowledge construction, and was designed to engage students in higher levels of thinking. The approach to self analysis is discussed in terms of its modification for use in other contexts and implications for practice are presented.
\end{abstract}

\section{Introduction}

An asynchronous, text based environment available through online discussion forums can provide many learner oriented benefits. Jonassen (2000) notes the important role of online asynchronous discussions (OADs) in online courses for "disseminating information", supporting communication and engaging learners in "evaluating information, discussing options, solving problems, and justifying their decisions, all of which require critical thinking" (p.266). From a theoretical perspective, online discussions can support opportunities for co-construction of knowledge through shared discourse and interaction with others in a social context. In this regard, OADs provide support for the types of student involvement and engagement advocated by social interactionist theories such as those of Vygotsky. Markel (2001) observed the explicit connection between what may go on in an OAD and the types of behaviors in which learners engage in a context of social interaction: 
Vygotsky's models of learning involving social interaction of peers, the scaffolding by more able peers and the use of language as a mediation tool of cognitive development all have opportunities of enactment in the use of the discussion forum within a web course environment. (Maximizing Learning, II 2)

Disseminating, evaluating and discussing information and options, solving problems, thinking critically, co-constructing knowledge, and scaffolding by more able peers: these represent opportunities that might be afforded by and taken advantage of in an OAD. These opportunities and the benefits of online discussions do not, however, occur automatically. Some studies that have focused on the content analysis of transcripts of online discussions have found that attempts to engage learners in, for example, knowledge construction, critical thinking or problem solving have not always been successful. Kanuka and Anderson's (1998) analysis of the transcript of an online discussion had similar findings of that of Gunawardena, Lowe, and Anderson (1997). In both cases, coding of discussants' postings placed them in the lower phases of a knowledge construction process:

Most of the conversation was of a sharing and comparing nature.

Dissonance and inconsistency were not actively explored, little testing of evidence against experience or the literature was expressed, and rarely did participants state the relevance or application of new knowledge that was created (Kanuka \& Anderson, 1998, Discussion section para 2)

Murphy's (2004) analysis of an OAD transcript for evidence of collaboration found that discussants did not reach high levels of collaboration but instead engaged in more individual rather than group oriented processes. Likewise, analysis of the transcript of an OAD designed to engage participants in problem formulation and resolution revealed that, while participants engaged in the resolution processes, they did not engage much in problem formulation even though this was an expected outcome in the design of the OAD (see Murphy, 2004b).

These results suggest that, even in cases where an instructor or designer may have intentionally structured, organised or moderated the discussion in order to promote engagement in a particular cognitive process such as knowledge construction, there is no assurance that these intentions will affect learning outcomes. This lack of assurance makes evaluation of the discussion a priority and can reveal whether or not students engaged in a particular intended process and if the discussion was effective in promoting understanding and learning. However, although it serves an essential purpose, the instructor's evaluation of the quality of postings of each student in a course can be an onerous, cumbersome and daunting task. As an alternative, instructors might opt to reply solely on simple quantitative analyses such as those that emphasise the value of the number 
and length of postings yet these will not provide in depth insights into the quality of learning.

An alternative approach to the evaluation of students' contributions to online discussions might be to directly involve students in a process of making sense of, interpreting and analysing their own performance in such contexts. Support for this approach comes from Knowlton (2000) who argues that "For the benefits of online discussions to be realised, students must have formal opportunities for self evaluation" (Broadening the Powers of Evaluation: Self Evaluation, II 1). He proposes a 'Self Analysis Model' that encourages students to metacognitively examine their own contributions to a discussion forum.

Student self assessment and self analysis are recognised in the literature as effective approaches to evaluation that can result in the development of higher order thinking and metacognition skills (Hansen, 1994) and improved student learning (Black and Wiliam, 1998). Such approaches conceptualise assessment not only as a means for grading and reporting but as a means for learning. Self assessment also has theoretical support in Schön's (1987) work on reflective practice which conceptualises learning as cyclical, developmental process that assesses existing knowledge and identifies gaps in order to improve learning in the future.

The purpose of this paper is to presents an illustrative case of how students can conduct a guided and systematic qualitative and quantitative analysis of their contribution to an online discussion. The case highlights the types of high level analyses students might engage in order to summatively assess their performance as well as identify ways of improving their future learning in online discussions. According to this approach, students conduct a self analysis of their contributions to the discussion using criteria supplied in advance of the discussion by the instructor. The student can subsequently present his self analysis of the discussion to the instructor at the end of the course or activity. It is this analysis that the instructor can then evaluate in order to provide a grade related to the student's participation in and contribution to the discussion. The following section of this paper presents one student's self analysis of his contribution to a discussion forum. The student's presentation is preceded by a section on methodology which explains the requirements of and context for the analysis.

\section{Methodology}

The discussion took place in the context of a graduate level education course. The student's analysis includes an examination of all messages that he posted in the course's four modules during weeks two to eleven 
inclusive. Weeks one, twelve and thirteen were not included as students were not required to engage in content related discussion during these periods. Also included in the analysis were postings from other discussion topics or folders such as Questions about presentations, Staff lounge and Group memberships for module 4 (see Murphy, 2003). The analysis was completed in three parts. Part I focuses on the number of messages, their distribution over the modules and their length. For Part II of the analysis, the student was required to examine the content of his postings in relation to claims and grounds. This requirement drew on an adaptation of Toulmin's (1958) models of argumentation and involved identifying claims made in each message and classifying them in one of three categories as follows:

1. Fact: claims focusing on phenomena that can be empirically verified;

2. Judgment/Value: claims involving opinions, attitudes or subjective evaluation;

3. Policy: claims advocating courses of action that should be undertaken.

Grounds were described as proof or evidence that can be used to support claims and had to be identified in relation to the following types: i) anecdotal evidence ii) quotations iii) reports iv) statistics v) findings vi) physical evidence vii) various forms of reasoning.

Part III required a critical assessment designed to demonstrate how the student advanced the discussion and promoted knowledge construction. The findings for this part had to be presented not numerically but by including quotes from the student's actual messages or postings. Part IV involved drawing overall conclusions related to the analysis both in terms of participation in the discussion and also in terms of completing the self analysis. In this regard, the student was expected to articulate what might be some of the implications for his future participation in online discussions.

This part of the analysis was also expected to include a reflection of how he could have participated more effectively in order to promote greater sharing and construction of knowledge. The following sections present an illustrative example of one student's self analysis as it was submitted to the instructor. The self analysis is followed by a discussion of this approach to the evaluation of participation in an online discussion. The discussion is followed by some general conclusions and consideration of some implications for practice.

\section{Part I: Analysis of participation}

The quantitative analysis of my contribution to the online discussion forum will include a count of the total number of postings made during weeks two to eleven of the course, the average length of the postings, the longest 
and shortest postings that were made, a brief examination of the varying lengths of messages, and consideration of how the postings were distributed over each of the four modules that comprised the course. The results of how the messages were distributed over the four modules of the course are presented in table format (Table 1) and a histogram (Figure 1).

Table 1: Distribution of my postings over four modules and nine weeks

\begin{tabular}{|c|l|c|c|}
\hline Module no. & \multicolumn{1}{|c|}{ Module title } & Weeks & Postings \\
\hline 1 & Multiple contexts: Multiple issues & $2,3,4$ & 7 \\
\hline 2 & Digital repositories and learning objects & 5,6 & 2 \\
\hline 3 & Asynchronous communication & 7,8 & 2 \\
\hline 4 & Collaborative online learning & $9,10,11$ & 37 \\
\hline
\end{tabular}

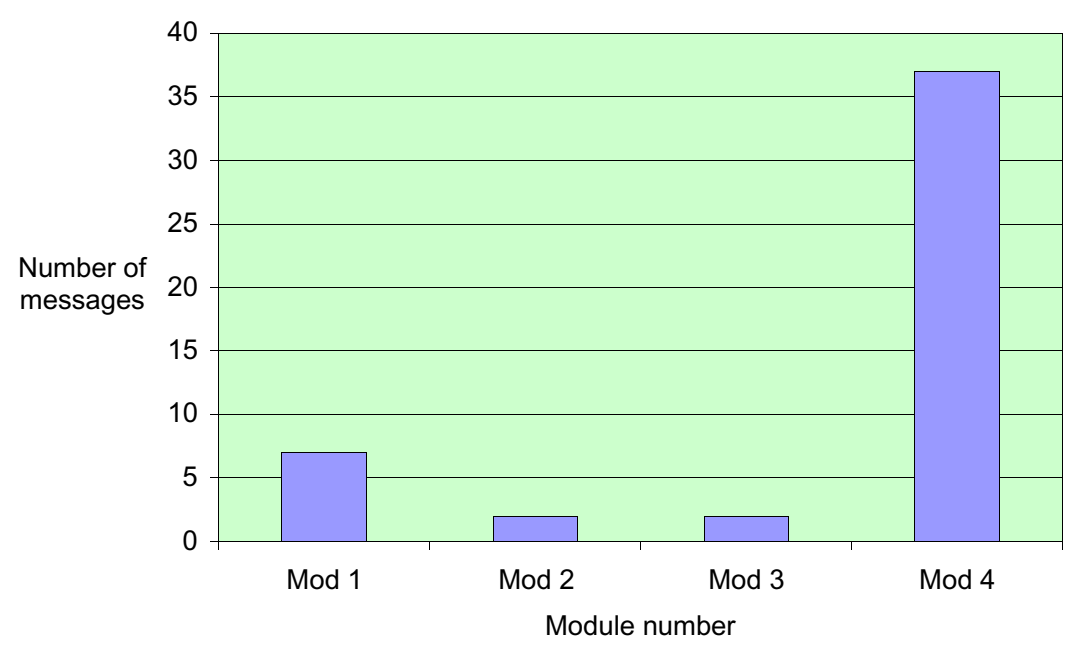

Figure 1: Distribution of my postings over four modules

As revealed in Table 1 and Figure 1, the majority of my postings were made in the completion of Module 4 of the course. To account for the larger number of postings in Modules 1 and 4, as compared with Modules 2 and 3 , one can observe from Table 1 that Modules 1 and 4 were both spread out over a three week period, whereas Modules 2 and 3 were only two weeks in length. Module 4 also involved the completion of a small group (3 members) online collaborative project and it is interesting to note that approximately twenty-four of my thirty-seven messages were directly related to this project.

The total number of messages I posted during weeks two through to eleven was forty-eight (48). The average length per posting was 


$$
\frac{\text { total number of words }}{\text { total number of postings }}=\frac{8221}{48} \approx 171 \text { words }
$$

My longest message of 1031 words was posted during Week 05, and was in response to a series of questions asked regarding the sharing of resources, an aspect of Module 2. I posted the shortest message of 6 words during Week 10 in the Group 3 section of the discussion forum. The posting was in response to a question asked by another group member regarding the version of Windows installed on my computer.

A summary of the above results is provided in Table 2.

Table 2: Summary of my posting length

\begin{tabular}{|l|c|}
\hline average length of postings & $\approx 171$ words \\
\hline longest message posted & 1031 words \\
\hline shortest message posted & 6 words \\
\hline
\end{tabular}

Figure 2 below provides a visual representation of the length of my postings and the number that falls into the following categories of message lengths: 0-100 words, 101-200 words, 201-300 words, 301-400 words, 401500 words, 501-600 words, 601-700 words, $>700$ words.

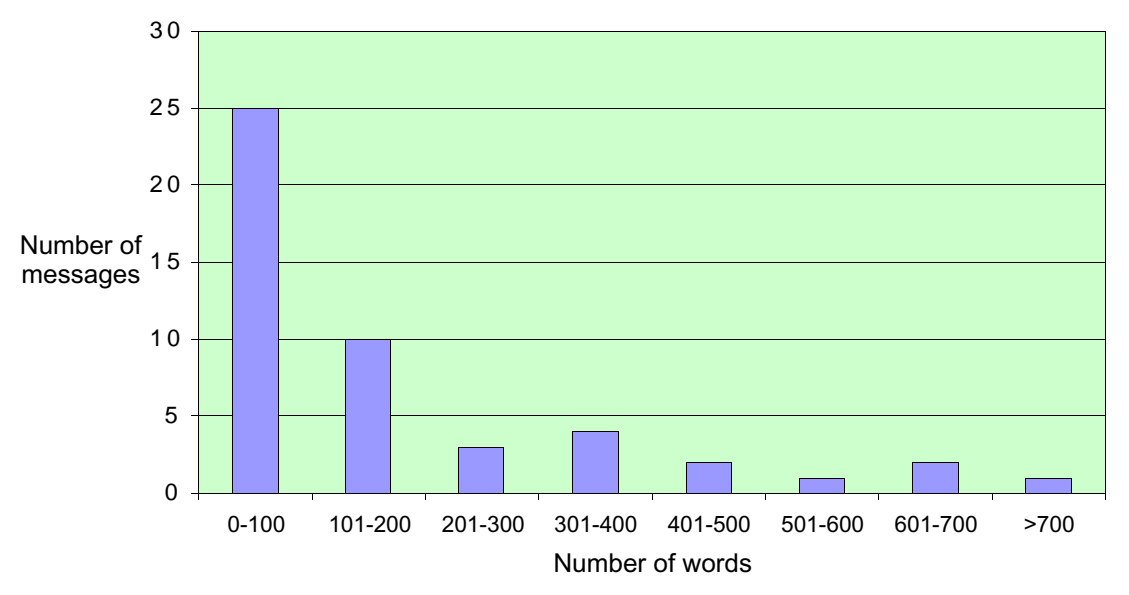

Figure 2: Summary of my posting length

\section{Part II: Analysis of claims and grounds}

The analysis of my postings revealed that they provided more than one type of claim. This is especially true of the more lengthy postings. As a result, the various categories of claims used in the analysis also include the 
possible combinations of claims that may exist within each of the postings, as shown in Table 3, rows 4 to 7 in the column for Type of claim.

My analysis revealed that I provided more than one type of evidence or proof in support of a particular claim. For the sake of simplicity, the chosen unit of analysis is the message itself, and though several claims may have been present in a particular message, the message has been categorised on the basis of evidence of a certain type of claim or claims. For example, if a posting made three Judgment/Value claims and a Policy claim, I classified it under "J/V \& $\mathrm{P}$ ".

Table 3: Claims contained in messages

\begin{tabular}{|l|c|}
\hline \multicolumn{1}{|c|}{ Type of claim } & $\begin{array}{c}\text { No. of messages providing } \\
\text { evidence of claim type }\end{array}$ \\
\hline Fact (F) & 1 \\
\hline Judgment/Value (J/V) & 5 \\
\hline Policy (P) & 2 \\
\hline Fact and Judgment/Value (F \& J/V) & 5 \\
\hline Fact and Policy (F \& P) & 0 \\
\hline Judgment/Value and Policy (J/V \& P) & 5 \\
\hline Fact, Judgment/Value and Policy (F, J/V \& P) & 20 \\
\hline No Claim (NC) & 5 \\
\hline
\end{tabular}

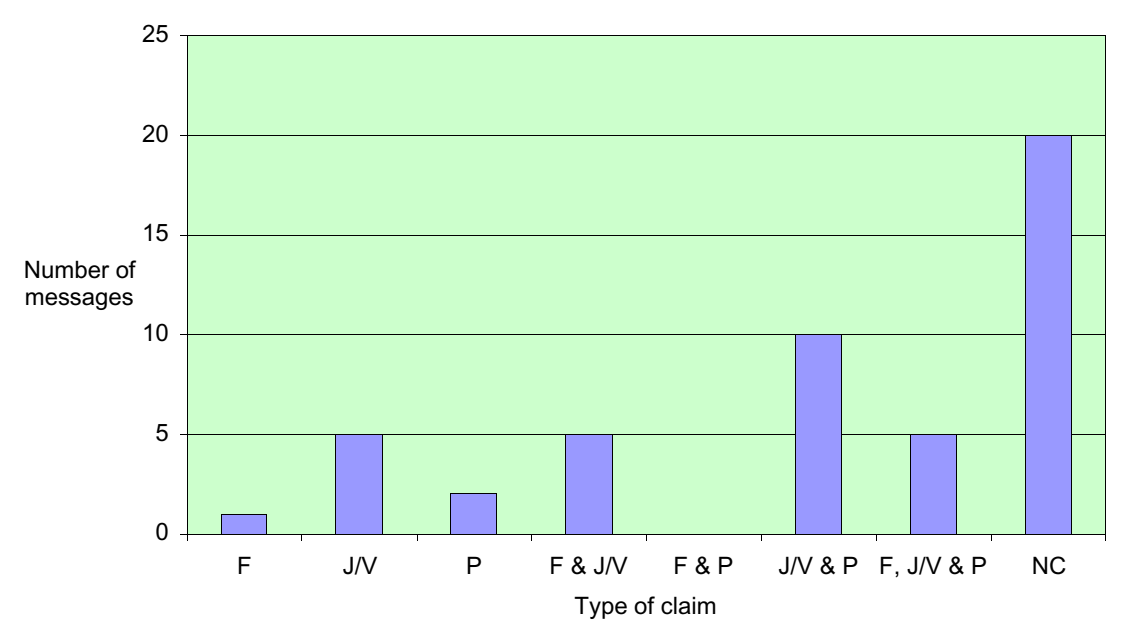

Figure 3: Claims contained in messages

Of my forty-eight messages, twenty-eight contain claims of various types. This is not to imply that only twenty-eight claims were made in contributions to the discussion forum. Instead, this means that twenty- 
eight of my postings contain evidence of a claim or claims being made of the various types. The results from the analysis of my postings in relation to the types of claims for the entire time period under consideration are provided in Table 3 and Figure 3.

Table 4 and Figure 4 illustrate the distribution of types of claims over the four modules.

Table 4: Distribution of my claims over modules

\begin{tabular}{|l|c|c|c|c|}
\hline \multirow{2}{*}{ Type of claim } & \multicolumn{5}{c|}{$\begin{array}{c}\text { Number of messages providing } \\
\text { evidence of claim type }\end{array}$} \\
\cline { 2 - 5 } & Mod 1 & Mod 2 & Mod 3 & Mod 4 \\
\hline Fact (F) & 0 & 0 & 0 & 1 \\
\hline Judgment/Value (J/V) & 2 & 0 & 0 & 3 \\
\hline Policy (P) & 0 & 0 & 0 & 2 \\
\hline Fact and Judgment/Value (F \& J/V) & 2 & 0 & 1 & 2 \\
\hline Fact and Policy (F \& P) & 0 & 0 & 0 & 0 \\
\hline Judgment/Value and Policy (J/V \& P) & 3 & 1 & 1 & 5 \\
\hline Fact, Judgment/Value and Policy (F, J/V \& P) & 0 & 1 & 0 & 4 \\
\hline No Claim (NC) & 0 & 0 & 0 & 20 \\
\hline
\end{tabular}

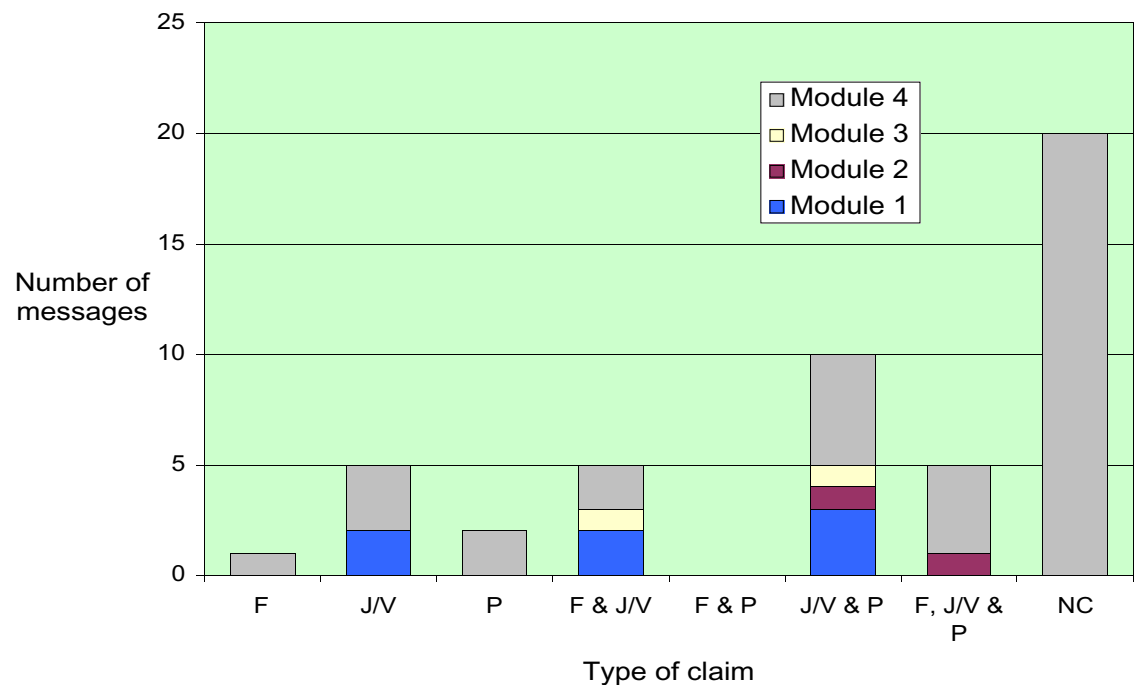

Figure 4: Distribution of my claims over modules

Supporting what one has to say through evidence and/or proof is important in establishing credibility and in encouraging others to listen and respect a particular perspective or view. In my twenty-eight postings in which I made claims, I found evidence of the following grounds: 
anecdotal evidence, quotations, reports, findings, physical evidence, and forms of reasoning. I did not provide statistical evidence to support any of my claims.

My analysis revealed that I provided more than one type of evidence or proof in support of a particular claim. Since some of my messages consisted of two or three claims, I provided different grounds to establish credibility for the points being made. The first set of results reflects the grounds evidenced in all twenty-eight messages containing claims, and further analysis will reveal the various types of evidence and proof provided in each of the modules.

Table 5: Grounds used in messages containing claims

\begin{tabular}{|l|c|}
\hline \multicolumn{1}{|c|}{ Grounds } & $\begin{array}{c}\text { Number of messages } \\
\text { using grounds type }\end{array}$ \\
\hline Anecdotal Evidence (AE) & 14 \\
\hline Quotations (Q) & 3 \\
\hline Reports (REP) & 2 \\
\hline Findings (F) & 17 \\
\hline Physical evidence (PE) & 6 \\
\hline Forms of reasoning (REAS) & 23 \\
\hline
\end{tabular}

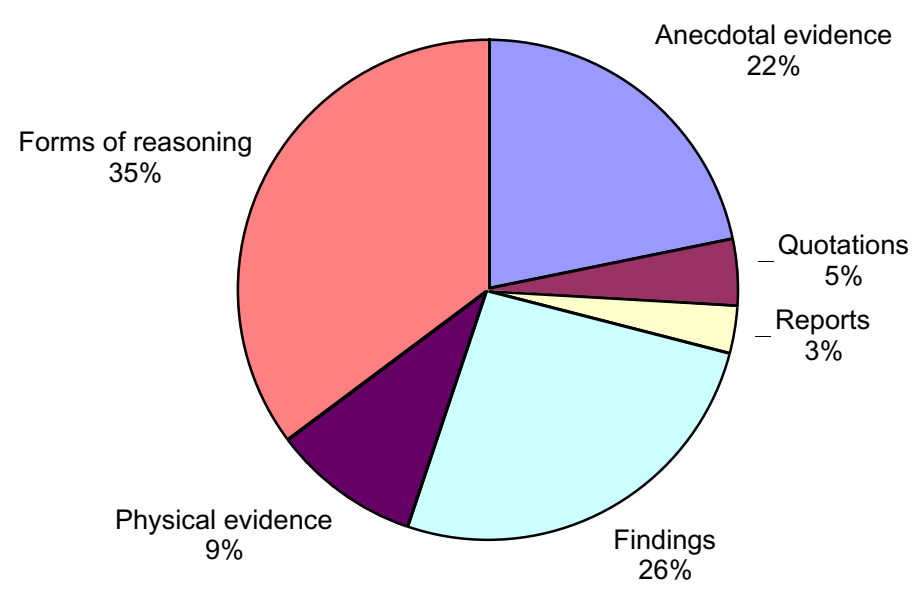

Figure 5: Grounds used in messages containing claims

As depicted in Table 5 and Figure 5, I relied on various forms of reasoning, findings, and anecdotal evidence for the grounds related to the various claims. Table 6 and Figure 6 provide a breakdown of the grounds I used in the claims over the four modules. 
Table 6: Grounds evidenced in the four modules

\begin{tabular}{|l|c|c|c|c|}
\hline \multirow{2}{*}{ Grounds } & \multicolumn{5}{|c|}{$\begin{array}{c}\text { Number of messages providing } \\
\text { evidence of grounds }\end{array}$} \\
\cline { 2 - 5 } & Mod 1 & Mod 2 & Mod 3 & Mod 4 \\
\hline Anecdotal Evidence (AE) & 3 & 1 & 1 & 9 \\
\hline Quotations (Q) & 0 & 1 & 1 & 1 \\
\hline Reports (REP) & 1 & 0 & 0 & 1 \\
\hline Findings (F) & 3 & 2 & 2 & 10 \\
\hline Physical Evidence (PE) & 1 & 1 & 0 & 4 \\
\hline Forms of Reasoning (REAS) & 6 & 2 & 2 & 13 \\
\hline
\end{tabular}

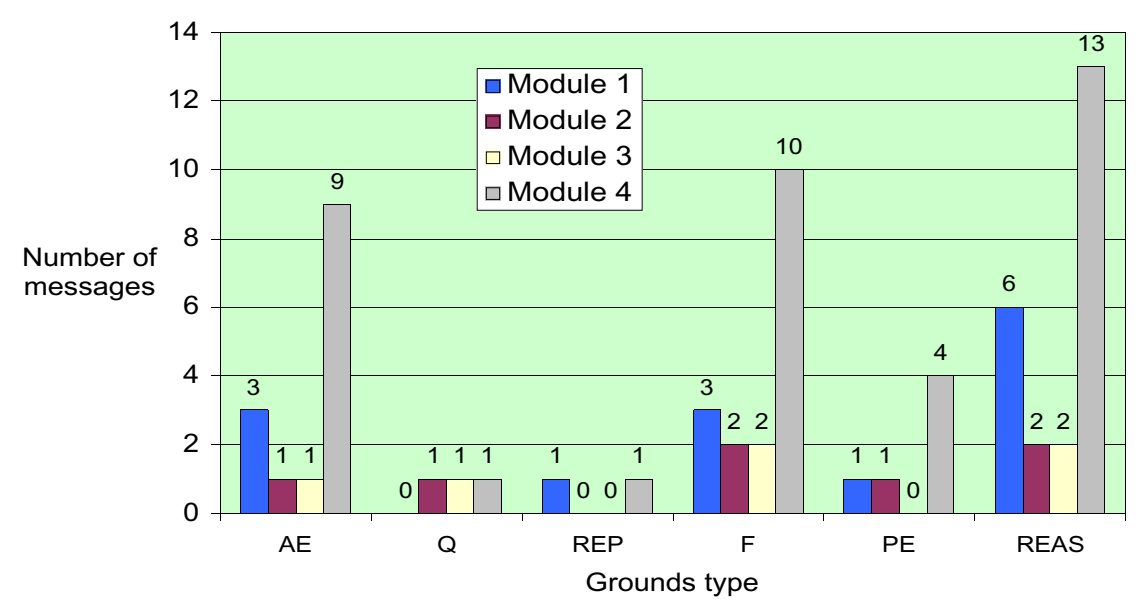

Figure 6: Grounds evidenced in the four modules

On closer examination of the course modules, I observed that I relied extensively on anecdotal evidence, findings, and forms of reasoning to provide evidence and proof for the claims I made. It is interesting to note that twenty-five of the twenty-eight messages that make claims are categorised as a judgment/value claim. Claims were only categorised as 'fact' if empirical evidence was provided in the message or if I made the claim based directly on research I had previously conducted. Modules 2 and 3 both contain only two postings, yet, all three types of claims are evidenced in each of the modules through the two messages. The length and detail of my postings, no doubt, contributed to this result.

The twenty messages which I characterised as having 'No Claim' all came from the completion of Module 4. Many of these messages were from the Group 3 section of the discussion forum and reflect the communication that occurred in organising and participating in a group project. Several of the 
postings are of a social nature, and though such postings may not necessarily contribute to the construction of new knowledge, they can be very important in establishing group dynamics and ensuring the eventual success of the collaborative project.

\title{
Part III: Analysis of contributions to the discussion
}

As a student in a traditional classroom setting, or a learner in an online course, I have always been concerned with my level of participation and the extent of my contribution to discussions. I would characterise myself as a relatively quiet person, who prefers to listen rather than speak. I mentioned this in Message no. 468 of the online discussion forum:

\author{
Message no. 468 \\ Posted by Jamie Loveless on Sunday, July 6, 2003 1:38pm \\ Subject Jamie's Application Activity \\ Online Discussions... \\ ...by nature I am a relatively quiet person (those who know me personally \\ can attest to this...I think ;-)) and even in a group setting among peers where \\ conversation is occurring I am not an outspoken person...
}

Normally, when I decide to contribute to a large group discussion, whether face to face or online, it is because I believe I have something significant to add. My online postings are usually a result of careful reflection and are well thought through. The seemingly average number of postings is typical of my contribution to such a discussion forum. The tables and figures presented throughout this analysis provide evidence that many of my postings contained numerous claims of varying types, and a variety of grounds was used in supporting these claims.

One of the ways I try to contribute to a discussion is through not only responding to questions, but through posing more questions and disrupting mindsets as in the following examples:

(i). ...do on-line courses tap into a certain independent learning style that many of our current students fail to possess?

(ii). ...but what will happen to those students who, for whatever reason, are unable to make the necessary adjustment from the traditional classroom to the virtual classroom setting?

...Why, too, do we assume that our higher achieving students will succeed, regardless of the manner in which a course is offered? Is this always fair to our higher achieving students? 
I tend to use a similar questioning technique in responding to the postings of others. The intent is to not only try and engage further discussion, but to have readers of the message search within themselves for possible answers to the question and, in turn, facilitate the construction of new knowledge, or restructure existing knowledge domains. An example of this questioning is evident in the following excerpt of a posting, given in response to a question asked by another student:

I sometimes wonder if it is really the scheduling of the online tutorials that is the issue, or is it the fact that teachers are not really comfortable with the medium through which they are being asked to learn?!...or is it a combination of both?

Are some of the demands and expectations being placed on teachers who may have limited experience with technology too great?

In trying to advance the discussion and promote knowledge building, I aim to include a personal element in my posting to exemplify metacognitive activity taking place. If other learners witness the occurrence of personal reflection and introspection, they may be inclined to do the same. Challenging one's own thoughts and ideas and the creation of dissonance is a significant step in the learning process. The following two excerpts of postings illustrate this idea:

(i).

It can be rather startling to "take a step back", on occasion, to observe and reflect on how quickly things are changing in our education system,...

(ii).

... This, I know, is a personal reflection and may not apply to others in the class.

In trying to avoid repetition among postings, which would detract from reader interest, I attempted to add novel thoughts and ideas to stimulate further discussion and broaden awareness of a particular topic or issue. This is evidenced in the following preamble to the main contents of the message:

The responses posted thus far do a superb job explaining the importance of online collaboration and provide sound reasoning as to why online collaboration is used in the design and development of online courses.

A few additional thoughts...

I included references in some of my postings to either support my claims or to provide an example of some aspect of the contents of my message. On some occasions, I provided online references to valuable math Web sites I felt would benefit others as a result of my sharing them: 
(i).

...Consider, for example, the following Web site, useful for examining transformations of quadratic functions: http://www.exploremath.com/activities/Activity_page.cfm?ActivityID=14

(ii).

...free "Peanut Software" made available by Richard Parris at

http:/ / peanut.8m.net/, are examples of tools that can be used by mathematics educators and students.

In relation to the communication and interaction that occurred in the design and development of the Group 3 collaborative project, I also made important contributions to the social dimension of the discussion. Although the contents of these twenty messages may not have directly contributed to the construction of knowledge, they played a role in establishing group dynamics and in facilitating the collaborative learning process. Even informing the group of my personal situation throughout the last week of the group project was critical in maintaining the level of trust and confidence that had been established within our group. Many of my messages contained positive feedback in relation to the group's efforts, thus contributing to the sense of morale that characterised our group. The following three examples provide evidence of this contribution:

(i).

That's perfect. Also, if I happen to find any decent articles relating to topic 2,

I'll let you know.

I would like to delve into topic 3 ...if that's ok!?!

Keep in touch!

Jamie :-)

(ii).

WOW!!!!!!!!

The work you have done in the construction of the Web site is unbelievable...

(iii).

As you are probably aware, this week is going to be very hectic for me...getting married Saturday!...

I argue that the absence of this social, 'human', element would have hindered the group's eventual success and detracted from the learning that occurred through completion of the collaborative project.

The above examples illustrate various ways I consciously attempted to advance the discussion and promote knowledge construction. It is difficult, however, to determine the true effectiveness of my contributions in relation to the learning experienced by other students. From a personal perspective, I know there were many postings from other students that stimulated my thinking and that resulted in the reconstruction and reshaping of my own 
knowledge, yet I did not respond to these postings in the discussion forum. This observation supports Kanuka and Anderson's (1998) argument that "It may also be possible that the construction of knowledge is not an observable activity" (Discussion, II 5) and "individual participants might be processing information internally in a reflective manner but not sharing these thoughts with other participants" (Results, II 16).

\section{Part IV: Conclusion and implications}

In relation to how I might have improved my contribution, one notable concern relates to the length of my postings. Participants in the discussion forum may refrain from reading postings that are very long. Even though these messages may contain valuable content which could serve to enhance discussion, they may be overlooked because of the length. To contribute more effectively to the discussion in the future, in addition to shortening my messages, I also recognise that I will need to devote more time to reading and responding to the messages of other participants. On several occasions, I read messages posted by other students and intended to reply when time permitted, but failed to do so. Markel (2001) observed that, "It is possible to feel invisible in an online discussion forum if no one responds to an individual's postings" (Response as Key, II 2). For this reason, in discussion forums in the future, I will set a goal of responding to a certain number of postings each week.

In conclusion, by conducting a self analysis of my contribution to an online discussion forum, I have developed an increased awareness of the potential benefits resulting from ongoing participation in this asynchronous mode of communication, including the sharing of experiences, challenging one's own thoughts and frames of cognition, the construction of new knowledge, and promoting collaborative efforts. As well, this activity helped me reflect on how I present my ideas and views in an online setting and how I tend to interact with others in a virtual environment. Through this self analysis, I have discovered ways I can potentially improve my participation in online discussion forums which will prove valuable in similar virtual settings in the future.

\section{Discussion of the approach to self analysis}

The student's self analysis of his contribution to the discussion presents an illustrative example of how students can be given opportunities to gain insight into and reflect on their participation in and contribution to an online asynchronous discussion. The four part analysis was designed to carefully and strategically guide the student. Part 1 focused his attention on identifying quantity and rates of participation in relation to the number of postings made as well as their length. This part simply required numerical 
recognition of quantities of postings and lengths of messages. Part II involved identifying the types of claims and grounds made within each message. Activities included interpreting, categorising, classifying, differentiating and organising messages in relation to types of claims and grounds.

Part III was designed to bring the student to a deeper level of analysis which involved locating evidence of how the postings might have advanced the discussion and contributed to knowledge construction. This part of the analysis was also expected to draw on Parts I and II in order to evaluate the consequences of how, for example, the length of postings or their distribution might have affected others in the discussion. Part III engaged the student in cognitive processes related to evaluation, judging and critiquing. Finally, Part IV engaged the student in hypothesising, planning, drawing conclusions and considering implications. For example, it was at this stage that the student could consider the results of what might have happened in the discussion if he had participated differently.

The self analysis first focused on simple identification and descriptions of the number and length of postings, claims and grounds and on knowledge construction. It also required organising this information using graphs, charts and direct quotes from the discussion. The analysis was designed to engage the student, not only in cognitive processes related to describing or identifying but in higher levels of thinking such as interpretation, evaluation and concluding. Other contexts of self analysis of an online discussion might require that students assess additional aspects of their participation in and contribution to an online discussion. For example, students might be expected to determine and show evidence of how they engaged in critical thinking or in problem solving. Under these circumstances, the discussion would need to be structured or moderated to intentionally elicit this type of participation from students.

Students' results of their self analysis do not necessarily need to be presented using spreadsheet programs as was the case in the example presented in this paper. Students could use a table or simply not be asked to include a quantitative assessment of their postings. While the requirements of the self analysis can therefore vary depending on the context, there will always be a need to ensure that students engage in a variety of levels of cognitive processing. Additionally, this engagement should occur at the higher levels of analysis and interpretation and not simply at the levels of describing and recognising. Thus, instructors interested in involving their students in the assessment of their participation in and contribution to an online discussion will want to ensure that the self analysis, regardless of whether it involves critical 
thinking, problem solving or argumentation etc, requires engagement in higher level processes.

\section{Conclusion}

As online discussions become more common in teaching and learning, instructors and students will be called on to devise ways to enhance participation in and contributions to such discussions. One way this enhancement can be achieved is through requirements for students' self analysis of the discussion to provide them with an opportunity to actively reflect on how they communicated and interacted and, more importantly, how they advanced their own learning. The self analysis can present an opportunity for students to assess their strengths and weaknesses and improve their future participation in an online discussion. From an instructor's perspective, the self analysis can help ensure that the discussion meets the expected outcomes. From a practical perspective, the self analysis takes away some of the burden of assessment turning over the responsibility to the student.

At the same time, requiring of students that they complete a self analysis will mean that instructors will have to clearly articulate the expectations for and requirements of participation in the discussion. It will not be enough to simply specify participation requirements in terms of numbers of postings. Nor will it be sufficient to require of students that they think critically, problem solve or contribute meaningfully to the discussion. Specific processes and indicators of those processes will need to be articulated and ideally some models of best practices provided.

As an example, an expectation that students engage in critical thinking will require of the instructor or designer of the online discussion that they present prompts and activities related to the construct of critical thinking. Instructors or designers can refer to the literature on critical thinking to determine the specific indicators and activities that might be suited to that construct. Ultimately, students' self analyses may help the instructor gain insight into and evaluate the degree to which he or she has effectively structured, organised and moderated the discussion. In this regard, the experience of students' self analysis of the discussion can become a learning tool for the instructor as well as the student.

\section{References}

Black, P. \& Wiliam, D. (1998). Inside the black box: Raising standards through classroom assessment. Phi Delta Kappan, 80(2), 139-148. 
Gunawardena, C., Lowe, C. A. \& Anderson, T. (1997). Analysis of a global online debate and the development of an interaction analysis model for examining social construction of knowledge in computer conferencing. Journal of Educational Computing Research, 17(4), 397-431.

Hansen, J. (1994). Literacy portfolios: Windows on potential. In S. W. Valencia, E. H. Hiebert \& P. P. Afflerrbach (Eds), Authentic Reading Assessment: Practices and Possibilities (pp. 26-44). Newark, DE: International Reading Association.

Jonassen, D. H. (2000). Computers as mindtools for schools: Engaging critical thinking (2nd ed.). Upper Saddle River, NJ: Prentice-Hall Inc.

Kanuka, H. \& Anderson, T. (1998). Online social interchange, discord, and knowledge construction. Journal of Distance Education, 13(1). [viewed 27 Jun 2003, verified 26 Apr 2005] http://cade.athabascau.ca/vol13.1/kanuka.html

Knowlton, D. S. (2000). Promoting durable knowledge construction through online discussion. Middle Tennessee State University [viewed 31 Jul 2003, verified 26 Apr 2005] http:/ / www.mtsu.edu/ itconf/proceed01/11.pdf

Markel, S. L. (2001). Technology and education online discussion forums: It's in the response. Online Journal of Distance Learning Administration, 4(2). [1Aug 2003] http://www.westga.edu/ distance/ojdla/summer42/markel42.html

Murphy, E. (2004). Recognizing and promoting collaboration in online asynchronous discussions. British Journal of Educational Technology 35(4), 421-431.

Murphy, E. (2004b). Identifying and measuring problem formulation and resolution in online asynchronous discussions. Canadian Journal of Learning and Technology 30(1), 5-20.

Murphy, E. (2003). Syllabus for Education 6620. [viewed 30 Jun 2003, not found 26 Apr 2005] http://webct.mun.ca:8900/SCRIPT/82157200203/scripts/serve_home

Schön D (1987). Educating the reflective practitioner. London: Jossey-Bass Publishers.

Toulmin, S. (1958). Uses of Argument. New York: Cambridge University Press. 
Elizabeth Murphy is an Associate Professor of Educational Technology and Second-Language Learning at Memorial University of

Newfoundland, St. John's, Newfoundland, Canada. She has conducted several studies related to use of online asynchronous discussions in teaching and learning. These studies have focused on collaboration, critical thinking, and on problem formulation and resolution.

Jamie Loveless is a high school math teacher at Exploits Valley High (Maple Division), Grand Falls-Windsor, NL, Canada. He has recently completed the Master of Education Degree in Teaching and Learning offered through the Memorial University of Newfoundland.

Dr Elizabeth Murphy, Associate Professor, Faculty of Education Memorial University of Newfoundland

St. John's, Newfoundland, Canada, A1B 3X8

Tel: (709) 7377634 Email: emurphy@mun.ca

Website: http:/ / www.ucs.mun.ca/ emurphy/

Jamie Loveless, Teacher, Exploits Valley High (Maple Division)

Nova Central School District

Grand Falls-Windsor, NL, Canada, A2A 1T6

Tel: (709) 4894374 Email: jllovele@cdli.ca

Website: http://www.angelfire.com/ma4/jloveless/ 